\title{
Estudo do Comportamento do Aço API 5L X80 quando submetido à Soldagem por Processo Automatizado
}

\author{
(Study on the Behavior of API 5L X80 steel when subjected to Automated Welding Process)
}

\author{
Siderley Fernandes Albuquerque ${ }^{1}$, Raphael de Sousa Silval', Theophilo Moura Maciel', Daisy M. Almeida², Alexandre Queiroz \\ Bracarense $^{3}$ \\ ${ }^{1}$ Universidade Federal de Campina Grande-UFCG, DEM, LABSOL, Campina Grande, Paraíba, Brasil \\ ${ }^{2}$ Universidade Federal de Campina Grande-UFCG, DF, Campina Grande, Paraiba, Brasil \\ ${ }^{3}$ Universidade Federal de Minas Gerais-UFMG, DEM, LRSS, Minas Gerais, Belo Horizonte, Brasil \\ siderleyfernandes@yahoo.com
}

\begin{abstract}
Resumo
No Brasil, a soldagem de tubulações tem sido praticamente de forma manual, entretanto, a utilização de processos de soldagem automatizados têm crescido muito nos últimos anos, contribuindo para o maior controle dos parâmetros de soldagem, e conseqüentemente, a possibilidade de obtenção de juntas soldadas com melhores propriedades mecânicas. A soldagem de tubulações com aço API 5 L X80 ainda vem sendo avaliada no Brasil no que diz respeito aos melhores procedimentos, parâmetros e processos de soldagem; a aplicação de processos automatizados nas condições especificas de campo constitui em uma opção ainda incipiente no país por se discutir ainda a relação custo/benefício com a sua implantação. Logo, o objetivo deste trabalho é avaliar o comportamento na ZTA de juntas soldadas do aço API 5L X80 utilizados para transporte de petróleo e gás quando submetidos à soldagem com diferentes parâmetros, procedimentos e processos de soldagem, incluindo o processo automatizado; os resultados indicam além da redução da extensão e do tamanho de grão da ZTA a preservação da estrutura bainitica do metal de base nesta região nas soldagem executadas com processos automatizados.
\end{abstract}

Palavras-chave: aço API $5 L$ X80, soldagem automatizada, ZTA, microestrutura.

Abstract: The welding of pipes has been largely manual in Brazil, however, the use of automated welding processes have greatly increased in recent years, contributing to greater control of welding parameters, and consequently, the possibility of obtaining welded joints with better mechanical properties. The welding of pipes of API 5L X80 steel has been evaluated in Brazil considering to best practices, parameters and welding processes; the implementation of automated processes in the specific field conditions is relevant project and innovative design in this area. Therefore, the objective is to evaluate the behavior in the HAZ of the API 5L X80 steel used for transporting oil and gas when subjected to automated welding processes; the results indicated besides the reduction of HAZ extent grain size the preservation of bainitic structure in this region for robotic welding process.

Key-words: API 5 L X80 steel, automated welding, HAZ, microstructure.

\section{Introdução}

Atualmente no Brasil a demanda energética apresenta uma projeção crescente o que faz com que se intensifiquem os investimentos no setor de petróleo e gás, este fato justifica a procura por técnicas de menor custo para montagem de dutos. $\mathrm{Na}$ linha de redução de custos uma iniciativa é a utilização de tubos com menor espessura de parede e processos de soldagem com maior produtividade.

A característica citada para os tubos conduz à utilização de aços de alta resistência e baixa liga que possuem alta resistência a esforços, boa tenacidade e boa soldabilidade, função de

(Recebido em 29/02/2012; Texto final em 07/03/2012).

Artigo originalmente publicado no CONSOLDA 2011 uma combinação de baixo teor de Carbono e processos termomecânicos de fabricação.

Uma classificação de aços indicados para o transporte de petróleo e gás é especificada na API 5L [1], sendo o aço em estudo classificado como API 5L X80, vários trabalhos reportam a boa soldabilidade deste aço $[2,3,4,5]$.

Durante a soldagem destes aços, se a taxa de resfriamento é alta, a austenita enriquecida de carbono transforma-se parcialmente em martensita e a austenita restante fica retida à temperatura ambiente formando o microconstituinte $\mathrm{AM}$, que pode resultar em zonas de fragilização localizada que degradam a tenacidade na região de grãos grosseiros da zona termicamente afetada - ZTA GG [6]; logo, para que ocorra boa tenacidade na zona termicamente afetada - ZTA é importante observar a quantidade, tipo e distribuição do constituinte A-M ai presente [7]; Davis e King [8] enfatizam que a presença do constituinte A-M não é necessariamente nociva, depende da sua fração volumétrica, morfologia e dureza, fato também observado por 
Almeida et al. [5].

Para melhorar a tenacidade à fratura na ZTA, são selecionados procedimentos de soldagem que reduzam a fração volumétrica da martensita e do constituinte A-M e promovam aumento no percentual de microestruturas mais tenazes $[8,9]$; Bhadeshia \& Honeycombe [10] e Almeida et al. [5] mencionam a vantagem da bainita por apresentar boas propriedades de resistência e tenacidade.

A produção nacional deste aço é recente e sua soldagem circunferencial por processos automáticos encontra-se em fase de implantação.

O processo de soldagem manual por eletrodo revestido SMAW (Shielded Metal Arc Welding) tem ampla utilização por ser relativamente simples aplicável em todas as posições de soldagem e versátil quanto aos locais de realização. Uma limitação é sua produtividade baixa comparada à dos processos automáticos e a necessidade de mais pessoal por hora de soldagem.

Os processos automáticos têm grande produtividade devido às altas taxas de deposição de material, boa penetração, boa qualidade do metal de solda e demanda de menores equipes de trabalho comparado com o eletrodo revestido.

Um dos processos mais interessantes para a utilização em soldagem transversal de tubos é o de arame tubular FCAW (Flux Cored Arc Welding) que, alem das vantagens citadas, inclui benefícios metalúrgicos advindos dos agregados contidos nos fluxos que podem influir favoravelmente nas propriedades mecânicas do metal de solda. Quanto às vantagens operacionais inclui-se sua possibilidade de utilização em processos de soldagem automatizados devido ao fornecimento contínuo de arame.

O estudo atual faz uma análise da microestrutura, extensão, tamanho de grão e microdureza da ZTA de juntas soldadas do aço API 5L X80, utilizando processo GTAW de forma manual (Gas Tungsten Arc Welding) no passe de raiz, SMAW de forma manual e FCAW robotizado no enchimento e acabamento.

\section{Materiais e Métodos}

O material utilizado foram chapas de aço API 5L X80, cuja microestrutura do metal base é apresentada na Figura 1; esta chapa possui espessura de $19 \mathrm{~mm}$ e composição química apresentada na Tabela 1; a composição química foi obtida por espectroscopia de massa.

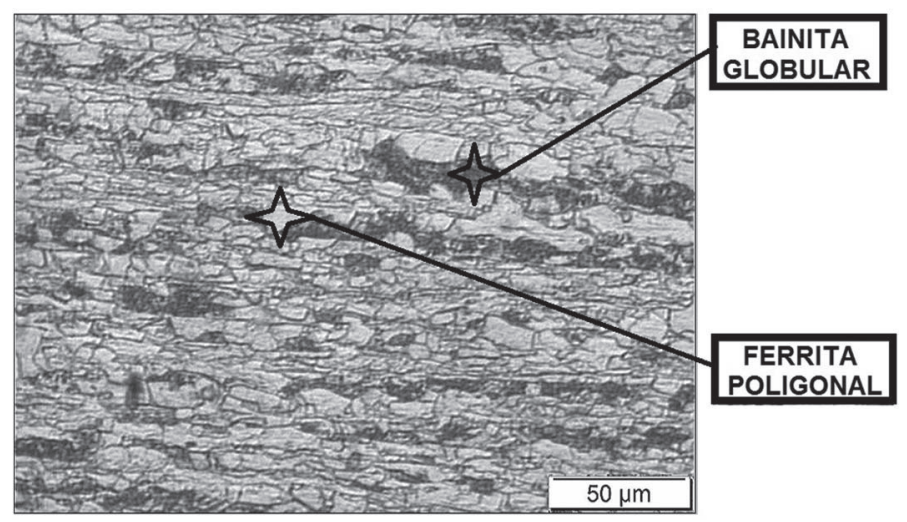

Figura 1. Microestrutura do metal base do aço API 5L X80.

Tabela 1. Composição química do aço API 5L X80 (Fe=97,912\%).

\begin{tabular}{|c|c|c|c|c|c|c|c|c|c|c|c|c|}
\hline $\mathbf{C}$ & $\mathbf{M n}$ & $\mathbf{S i}$ & $\mathbf{A l}$ & $\mathbf{P}$ & $\mathbf{V}$ & $\mathbf{C r}$ & $\mathbf{N i}$ & $\mathbf{M o}$ & $\mathbf{S}$ & $\mathbf{C u}$ & $\mathbf{N b}$ & $\mathbf{T i}$ \\
\hline 0,082 & 1,808 & 0,242 & 0,044 & 0,015 & 0,028 & 0,157 & 0,018 & 0,197 & 0,005 & 0,011 & 0,076 & 0,011 \\
\hline
\end{tabular}

Fundição Altivo (Contagem-MG).

Após o corte da chapa empregando processo de corte por plasma, realizou-se a usinagem do chanfro no formato de $1 / 2$ $\mathrm{V}$ com nariz e distanciamento do passe de raiz da ordem de $2 \mathrm{~mm}$; as chapas foram soldadas sem restrição, sendo necessária a utilização de uma pré-deformação no alinhamento da junta soldada, a fim de reduzir as distorções provenientes da soldagem.

Em seguida, as chapas foram soldadas utilizando-se as seguintes variações de consumíveis, processos e procedimentos de soldagem: (a) processos manuais a Arco Elétrico com Eletrodo Revestido (SMAW) para preenchimento da junta e passe de raiz, utilizando como consumível o eletrodo AWS ER 7018 com diâmetro de 2,4 mm para passe raiz e o eletrodo AWS E9010G com 3,2 mm para os passes de enchimento e acabamento; (b) processo TIG manual na raiz e ao Arco Elétrico com Arame Tubular (FCAW) robotizado nos passes de enchimento e acabamento, utilizando como consumível o arame ER80S-Ni1 com diâmetro de 2,4 mm e argônio como gás de proteção no processo TIG, e o arame AWS E111T1-K3MJ-H4 com diâmetro de 1,2 mm e argônio com $25 \%$ CO2 como gás de proteção no processo FCAW.

Para avaliar o efeito da posição de soldagem as juntas foram soldadas na posição plana e vertical ascendente. As amostras foram nomeadas de acordo com o processo utilizado e a posição de soldagem; logo, para soldagem manual com eletrodo revestido, utilizou-se a designação MP para posição na soldagem plana, e MA na posição de soldagem vertical; para soldagem robotizada com arame tubular no enchimento e TIG na raiz, utilizou-se a designação RP para posição na soldagem plana, e RA para posição na soldagem vertical. Na Tabela 2 têm-se os principais parâmetros utilizados, assim como a determinação do aporte térmico para cada procedimento de soldagem; procurou-se manter o aporte térmico semelhante para todos os procedimentos de soldagem. 
Tabela 2 - Parâmetros de soldagem utilizados.

\begin{tabular}{|c|c|c|c|}
\hline \multirow[b]{2}{*}{ Procedimento de soldagem } & \multicolumn{3}{|c|}{ Corrente de Soldagem (A) } \\
\hline & Passe de Raiz & Passe de enchimento & Passe de acabamento \\
\hline MP & 100 & 90 & 90 \\
\hline MA & 100 & 90 & 90 \\
\hline MS & 100 & 90 & 90 \\
\hline RP & 230 & 137 & 142 \\
\hline RA & 230 & 157 & 157 \\
\hline \multirow{2}{*}{$\begin{array}{l}\text { Amostra/ Posição de } \\
\text { Soldagem }\end{array}$} & \multicolumn{3}{|c|}{ Velocidade de Soldagem $(\mathrm{mm} / \mathrm{s})$} \\
\hline & Passe de Raiz & Passe de enchimento & Passe de acabamento \\
\hline MP & 1,66 & 1,31 & 1,62 \\
\hline MA & 0,87 & 1,18 & 0,76 \\
\hline MS & 1,19 & 1,82 & 2,08 \\
\hline RP & 2,27 & 2,66 & 2,66 \\
\hline RA & 1,78 & 3,00 & 3,00 \\
\hline \multirow{2}{*}{$\begin{array}{l}\text { Amostra/ Posição de } \\
\text { Soldagem }\end{array}$} & \multicolumn{3}{|c|}{ Tensão (V) } \\
\hline & Passe de Raiz & Passe de enchimento & Passe de acabamento \\
\hline MP & 19 & 19 & 19 \\
\hline MA & 19 & 19 & 19 \\
\hline MS & 19 & 19 & 19 \\
\hline $\mathrm{RP}$ & 10 & 23,5 & 23,5 \\
\hline RA & 10 & 23,5 & 23,5 \\
\hline \multirow{2}{*}{$\begin{array}{l}\text { Amostra/ Posição de } \\
\text { Soldagem }\end{array}$} & \multicolumn{3}{|c|}{ Aporte Térmico $(\mathrm{kJ} / \mathrm{mm})$} \\
\hline & Passe de Raiz & Passe de enchimento & Passe de acabamento \\
\hline MP & 1,14 & 1,31 & 1,06 \\
\hline MA & 2,18 & 1,45 & 2,25 \\
\hline MS & 1,60 & 0,94 & 0,82 \\
\hline $\mathrm{RP}$ & 1,01 & 1,21 & 1,21 \\
\hline RA & 1,29 & 1,23 & 1,23 \\
\hline
\end{tabular}

Foram realizados um total de 13 passes para o procedimento MP, 8 passes para o procedimento MA, e para os procedimentos RP e RA foram realizados 10 passes cada; o controle do número de passes não foi possível para o caso MP e MA devido ao escorrimento do cordão na soldagem fora de posição e na perda de metal decorrente da retirada de escória.

$\mathrm{Na}$ etapa metalográfica, utilizou-se lixas 100, 150, $220,400,500,600$ e 1200, com polimento utilizando as aluminas de números $2(0,05 \mu), 3(0,3 \mu)$ e $4(1 \mu)$; então, foram atacadas com Nital $2 \%$ para identificação dos microconstituintes na ZTA por microscopia óptica; a microestrutura foi analisada na região representada pela Figura 2 (a); seguindo recomendações da norma ASTM E112-10 [12], para determinação do tamanho de grão na ZTA, a partir de uma microestrutura com aumento de 500X, delimitou-se os contornos de grãos austeníticos, e utilizou-se a ferramenta para medições de tamanho grão por interceptos, disponível no programa Quantikov [11].
Para determinação do perfil de microdureza foram realizadas 5 identações por região da junta soldada, iniciando na linha de fusão (LF), depois na região de grãos grosseiros da ZTA (ZTA GG) e na região de grãos finos da ZTA (ZTA GF); as medições também foram feitas em três regiões ao longo da espessura da chapa, adjacente aos passes de acabamento, enchimento e passe raiz; posteriormente determinou-se uma média para cada região, conforme Figura 2 (b); utilizou-se o microdurômetro digital FM-700 Future Tech, com carga de 200 gf e distanciamento de $90 \mu \mathrm{m}$ entre cada indentação, seguindo recomendações da norma ASTM E 384-10 [13].

Para determinação da extensão da ZTA foram realizadas 20 medições por amostra, sendo 6 medidas na região adjacente ao passe de enchimento, 11 na região adjacente aos passes de enchimento e 3 na região adjacente ao passe de raiz, conforme representação esquemática na Figura 2 (c); por fim calculou-se uma média geral para cada região. 
GG GF

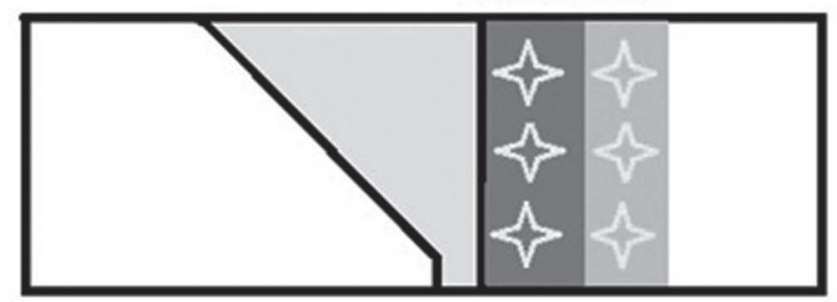

a

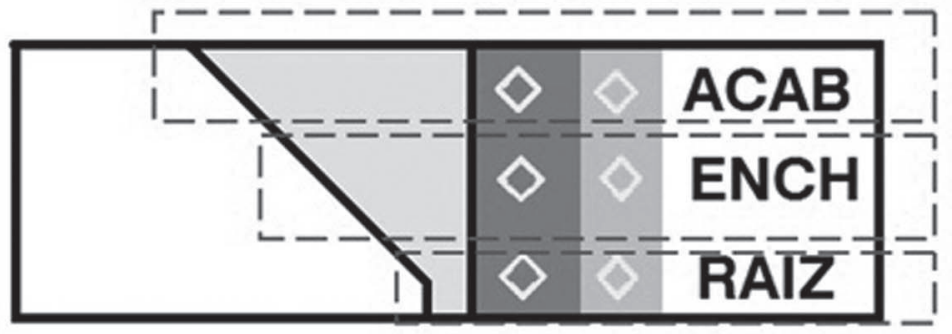

b

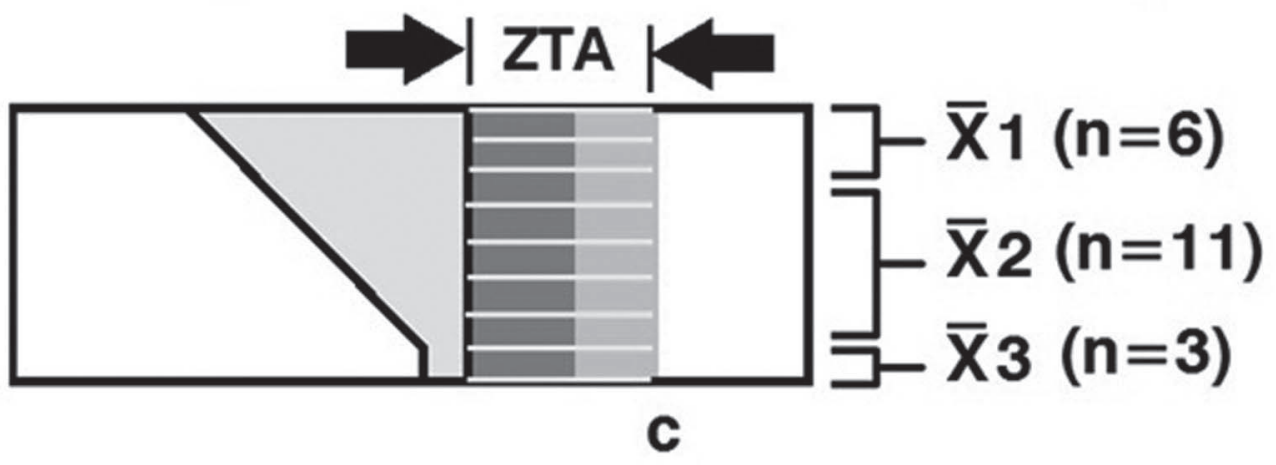

Figura 2 - Representação esquemática da metodologia utilizada. (a) análise da microestrutura na ZTA; (b) determinação da microdureza média junta soldada (c) determinação da extensão da ZTA.

\section{Resultados e Discussão}

\subsection{Extensão da ZTA}

A ZTA é a região de maior cuidado na junta soldada, mais especificamente a região de grãos grosseiros, considerada uma zona crítica e muito favorável ao surgimento de trincas; como o aço em estudo é um aço bainítico, pode apresentar nesta região microconstituintes frágeis como a martensita, além de constituintes A-M que dependendo da morfologia pode induzir a formação de trincas [14].

Pode-se observar a partir da Tabela 3 que as amostras soldadas com procedimento de soldagem manual (MP e MA), apresentaram valores médios de extensão de ZTA superiores as amostras soldadas com procedimento RP e RA, principalmente na região de enchimento, cuja influencia sobre a extensão da ZTA é mais significativa; observam-se reduções da ordem de $54,5 \%$ na região adjacente aos passes de enchimento.

Nos resultados da Tabela 3, apesar do aporte térmico na região de enchimento para todos os procedimentos ter sido aproximadamente o mesmo, observa-se que a extensão da ZTA é menor nos procedimentos RP e RA, consequência da maior velocidade de soldagem empregada. Isto foi possível com um aumento da corrente e tensão. Observa-se ainda que no procedimento MA, os valores de extensão da ZTA adjacente a região de enchimento e acabamento foram os maiores encontrados, isto ocorreu pelo maior aporte térmico observado nos passes de acabamento (relacionado à baixa velocidade de soldagem) e sua influência sobre os passes de enchimento; o soldador encontra maior dificuldade na soldagem vertical ascendente, tanto pela posição de soldagem quanto pelo escorrimento do cordão de solda sob o efeito da gravidade. Logo, ao invés de serem feitos 10 passes (como no procedimento RA), foram realizados 8 passes.

Tabela 3 - Valor médio de extensão da ZTA (mm)

\begin{tabular}{|c|c|c|}
\hline $\begin{array}{c}\text { PROCEDIMENTO } \\
\text { DE SOLDAGEM }\end{array}$ & $\begin{array}{c}\text { REGIÃO } \\
\text { DA ZTA }\end{array}$ & $\begin{array}{c}\text { EXTENSÃO } \\
\text { DA ZTA }\end{array}$ \\
\hline \multirow{3}{*}{ MP } & ACAB & $2,3 \pm 0,4$ \\
\cline { 2 - 3 } & ENCH & $3,6 \pm 1,2$ \\
\cline { 2 - 3 } & RAIZ & $5,25 \pm 0,8$ \\
\hline \multirow{3}{*}{ MA } & ACAB & $6,6 \pm 0,4$ \\
\cline { 2 - 3 } & ENCH & $5,5 \pm 0,7$ \\
\cline { 2 - 3 } & RAIZ & $3,7 \pm 0,3$ \\
\hline \multirow{3}{*}{ RP } & ACAB & $3,6 \pm 1,9$ \\
\cline { 2 - 3 } & ENCH & $2,8 \pm 0,3$ \\
\cline { 2 - 3 } & RAIZ & $3 \pm 0$ \\
\hline \multirow{3}{*}{ RA } & ACAB & $3,5 \pm 2,1$ \\
\cline { 2 - 3 } & ENCH & $2,5 \pm 1,1$ \\
\cline { 2 - 3 } & RAIZ & $4,7 \pm 0$ \\
\hline
\end{tabular}


Tabela 4 - Diâmetro de grão na ZTA $(\mu \mathrm{m})$.

\begin{tabular}{|c|c|c|c|c|}
\hline PROCEDIMENTO DE SOLDAGEM & REGIÃO DA ZTA & ACAB & ENCH & RAIZ \\
\hline \multirow{2}{*}{ MP } & GG & 58 & 46,5 & 38,5 \\
\cline { 2 - 5 } & GF & 5,6 & 7,1 & 7,4 \\
\hline \multirow{2}{*}{ MA } & GG & 73,5 & 75,5 & 47,5 \\
\cline { 2 - 6 } & GF & 3,8 & 3,8 & 4,05 \\
\hline \multirow{2}{*}{ RP } & GG & 53,5 & 43 & 42 \\
\cline { 2 - 6 } & GF & 7,4 & 7,1 & 6,5 \\
\hline \multirow{2}{*}{ RA } & GG & 47,5 & 42 & 51 \\
\cline { 2 - 6 } & GF & 3,1 & 4,1 & 4,7 \\
\hline
\end{tabular}

\subsection{Tamanho de Grão na ZTA}

O aumento do tamanho de grão está entre os principais fatores metalúrgicos que contribuem para baixa tenacidade na região de grãos grosseiros da ZTA [15], podendo influenciar significativamente na resistência mecânica e na tenacidade da junta soldada, principalmente em aços com maior limite de resistência como é o caso do aço em análise.

Na Tabela 4 tem-se o tamanho de grão para os procedimentos de soldagem estudados; tanto para região de grãos grosseiros (ZTA GG) quanto para região de grãos finos (ZTA GF); nas figuras 4,5 e 6 tem-se uma referência do tamanho de grão, indicado pela letra "G" nas fotos.

O tamanho de grão apresentou-se heterogêneo na região adjacente ao passe de raiz, aumentando nas regiões adjacentes aos passes de enchimento e acabamento; isto ocorre em função da influência do ciclo térmico do passe posterior, que é observado para soldagem multipasse, resultado também observado por Durand [16].

Observa-se que o crescimento de grão na ZTA GG foi mais significativo na região adjacente aos passes de acabamento e enchimento para o procedimento MA, com valores da ordem de $73,5 \mu \mathrm{m}$ e $75,5 \mu \mathrm{m}$, respectivamente; isto ocorreu em função do maior aporte térmico ao qual a junta soldada foi submetida, decorrente da redução da velocidade de soldagem pelo soldador; como a soldagem é na posição ascendente, existe o escorrimento do metal de adição, com maior deposição de material por cordão, caso a velocidade seja muito baixa.

No procedimento RA, têm-se reduções de tamanho de grãos de aproximadamente $35 \%$ e $44 \%$, respectivamente para região adjacente ao passe de acabamento e ao passe de enchimento; para os outros procedimentos, as variações são menos significativas.

$\mathrm{Na}$ região de grãos finos (ZTA GF), o tamanho de grão apresentou variação em função da posição de soldagem utilizada, ou seja, um maior refinamento para posição soldagem vertical ascendente.

\subsection{Microestrutura na ZTA}

Nas Figuras 3, 4 e 5 tem-se as microestruturas obtidas na ZTA GG e na ZTA GF, para todos os procedimentos de soldagem realizados, considerando as regiões adjacentes aos passes de acabamento, enchimento e raiz, o aumento utilizado foi de 500x.

Pelas figuras podem-se observar as estruturas mais refinadas e com presença de Bainita (B) na ZTA obtidas com os processos automatizados, favorecendo uma melhor relação entre resistência e tenacidade nesta região. Como o aço em estudo é bainítico, uma microestrutura bainítica na ZTA reduz a diferença destas propriedades na transição metal de base ZTA melhorando a qualidade final da junta soldada; esta diferença pode ser indiretamente avaliada através do perfil de dureza das amostras.

\subsection{Perfil de Microdureza}

Nas Figuras 6, 7 e 8 tem-se os valores médios de microdureza na ZTA nas regiões adjacentes aos passes de acabamento, enchimento e raiz, conforme procedimento ilustrado na Figura 2.

Pode-se perceber que os valores de dureza tanto na região de grãos finos quanto na região de grãos grosseiros das ZTA's obtidas com a soldagem manual, foram em geral inferiores àqueles obtidos com a soldagem automatizada, principalmente no passe de enchimento utilizando o procedimento MA. Neste caso a energia de soldagem foi muito mais elevada e não houve refinamento pelo passe subseqüente, (ver Tabela 5), proporcionando uma taxa de resfriamento muito baixa e, consequentemente uma redução na dureza, aumentando a possibilidade de formação de Ferrita de Widmasttaten na ZTA, e queda significativa na resistência mecânica da junta, o que é preocupante para os aços ARBL, cujo principal objetivo é possuir alta resistência mecânica associada à boa tenacidade [17].

Durand [16], Linnert [18] e Ordónez [19] também observaram que na soldagem mutipasse de aço API 5L X65 e X80, o aumento na energia de soldagem propiciou uma redução da taxa de resfriamento, causando aumento do tamanho de grão na ZTA com a conseqüente queda de dureza nesta região.

No passe de enchimento não se observa uma diferença muito significativa nos valores de microdureza, entretanto, continuam em média inferiores aos obtidos com os procedimentos empregando processo automatizado.

Já nos passes de raiz observa-se uma irregularidade elevada nos valores de dureza nas soldagens executadas com o 


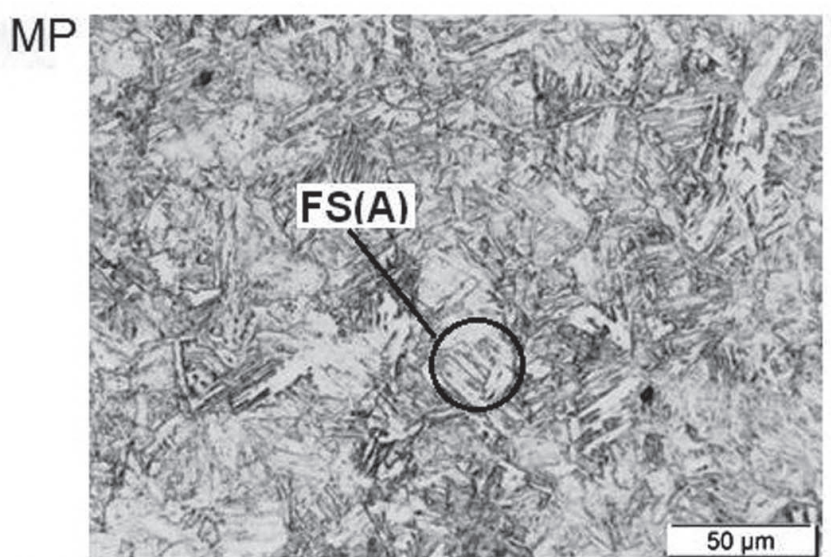

RP

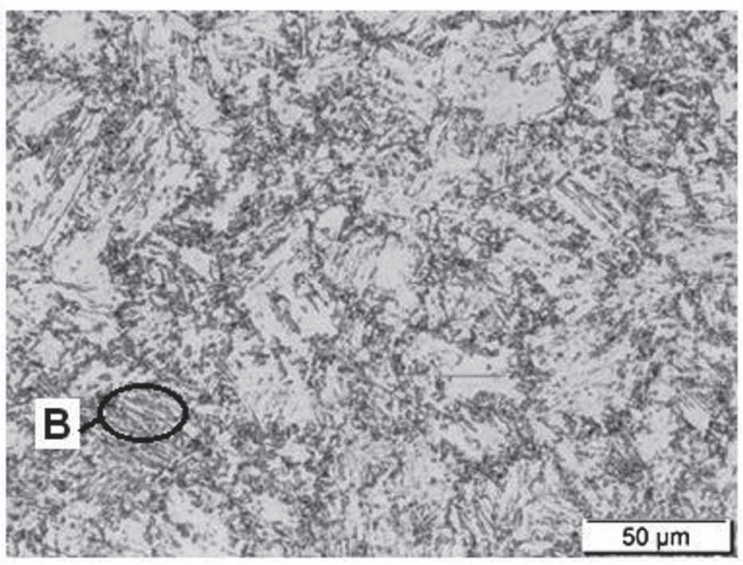

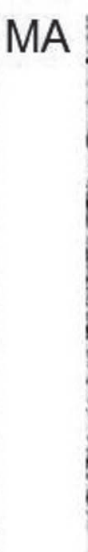
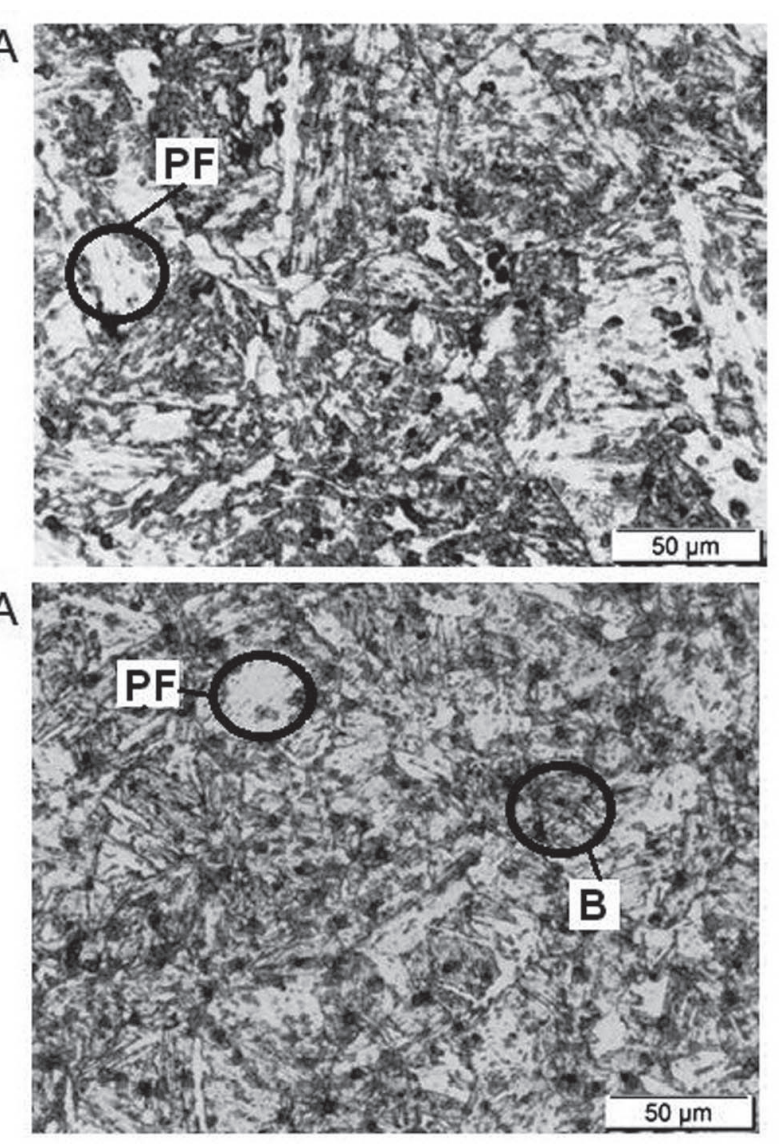

0
$\mathbf{N}$
$\mathbf{N}$
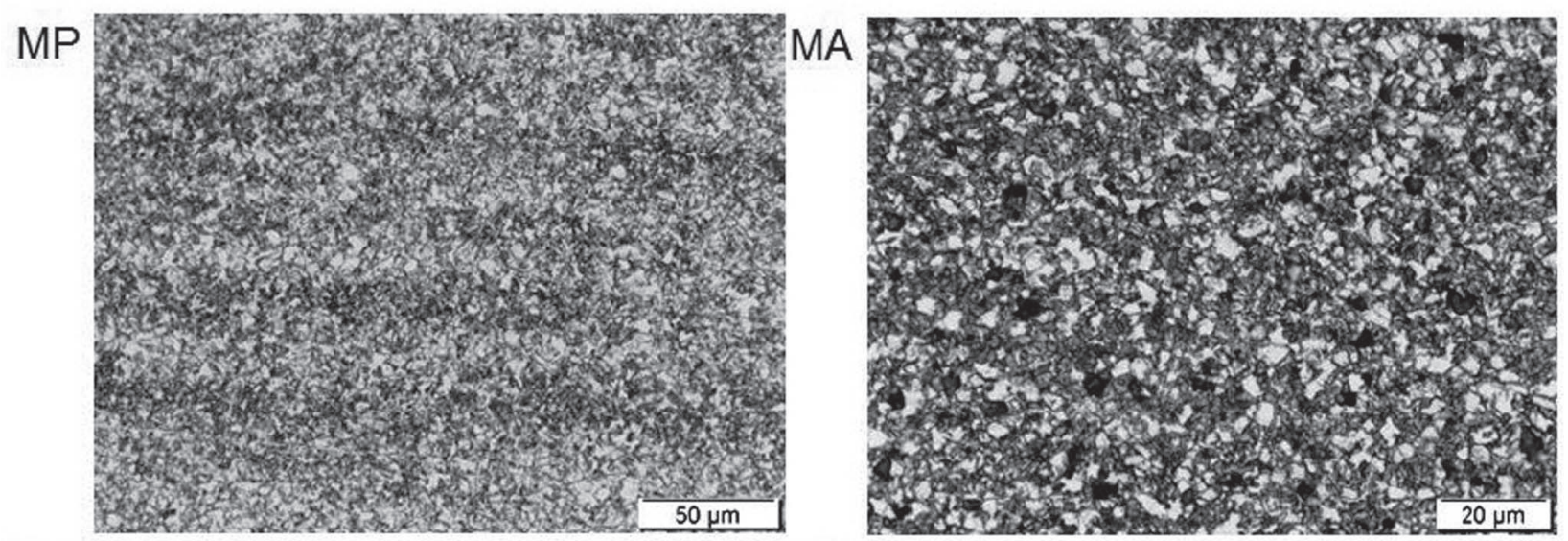

$\mathrm{RP}$

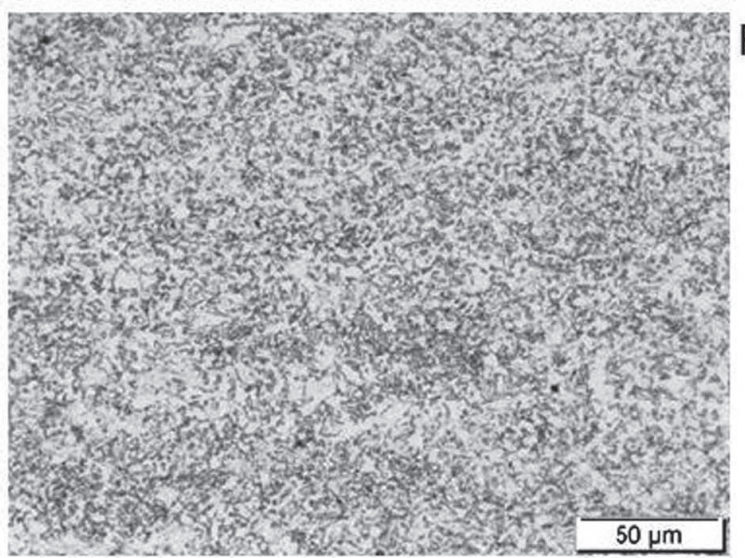

RA

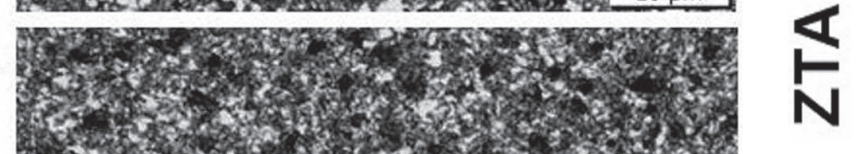

Figura 3. Microestrutura na ZTA adjacente aos passes de acabamento. PF-Ferrita Primária, B-Bainita. 
MP

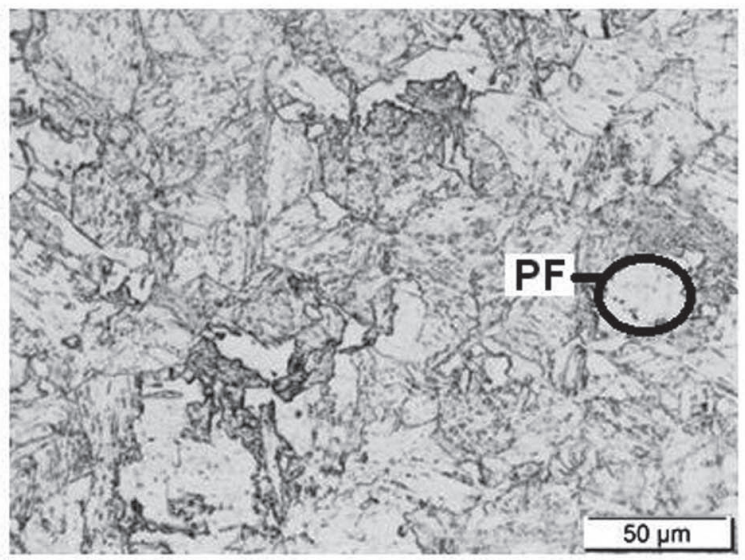

$\mathrm{RP}$

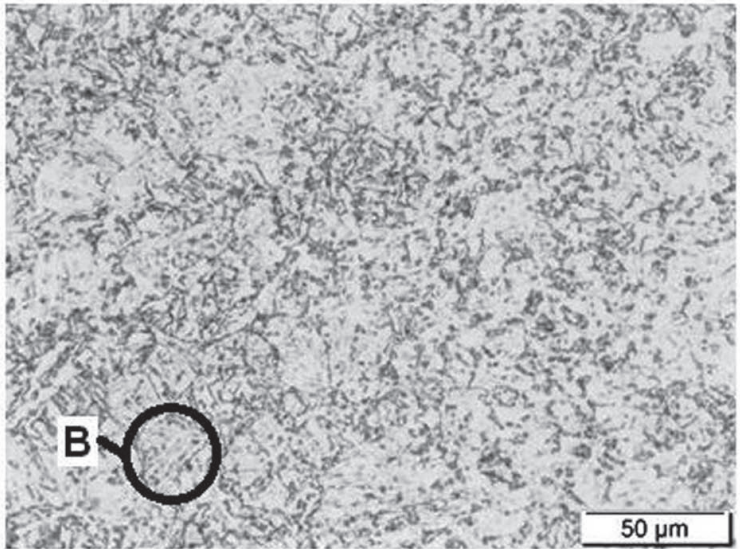

MA

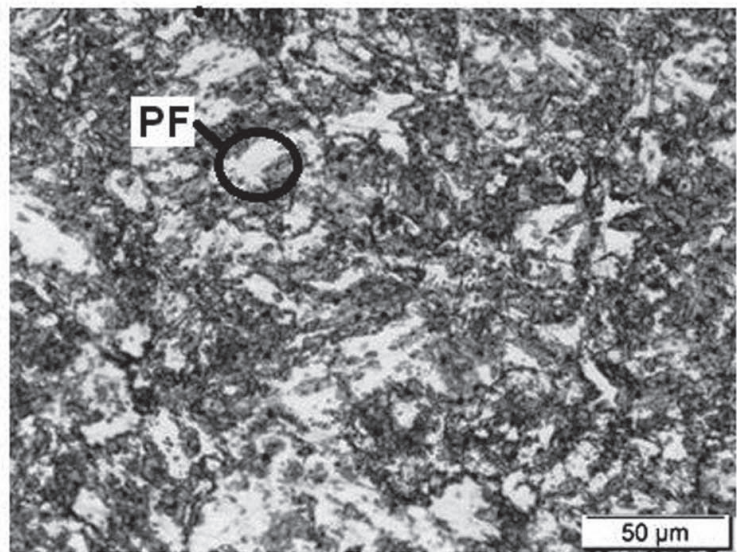

RA

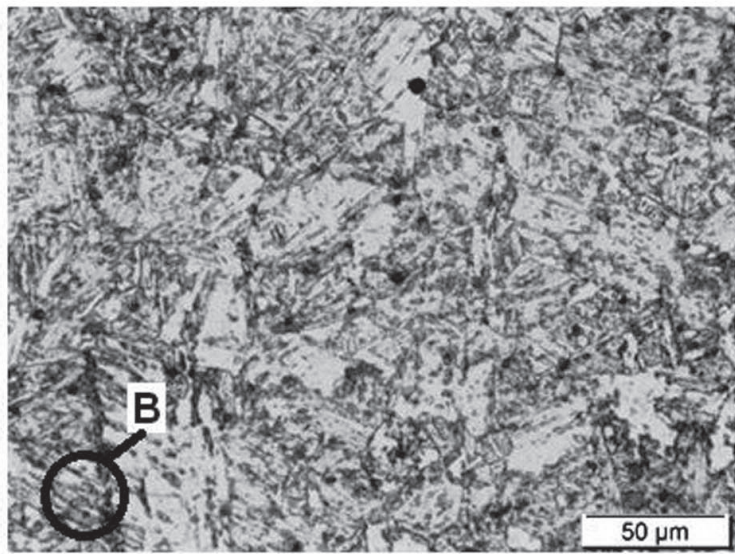

$\mathrm{RP}$

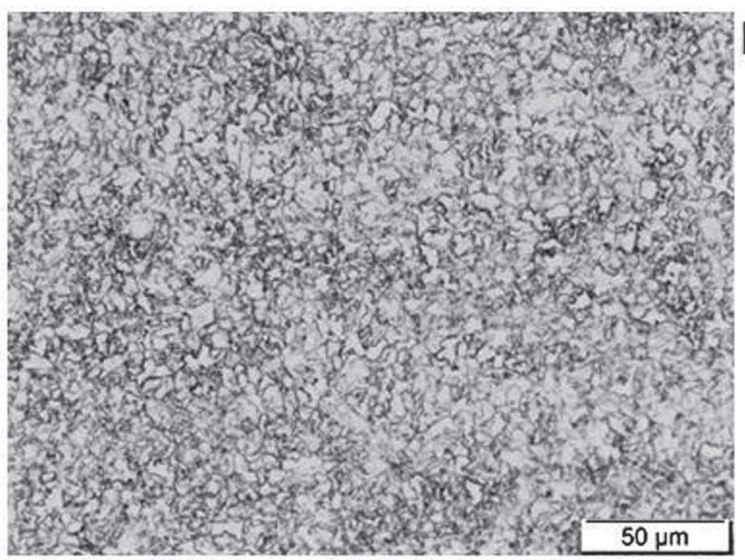

MA

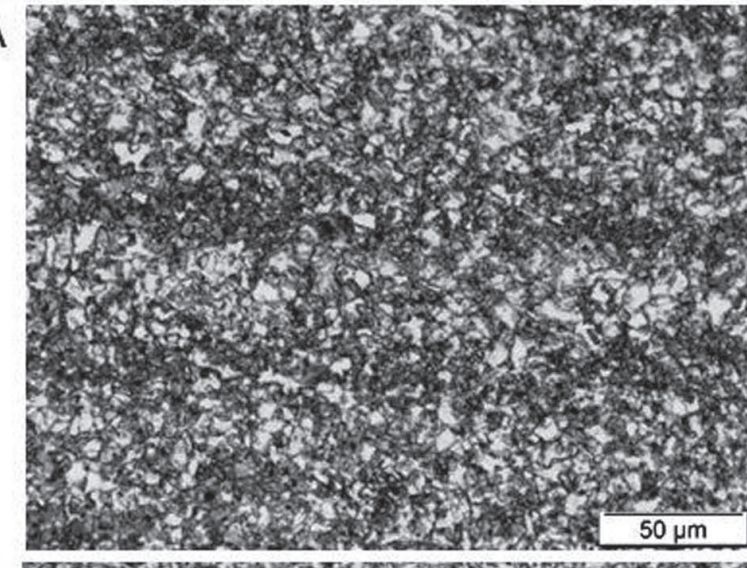

RA

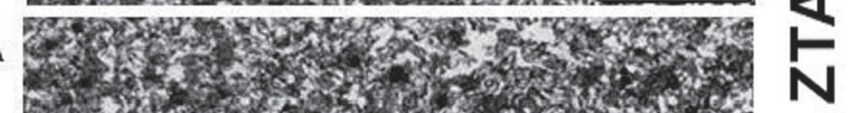
T.

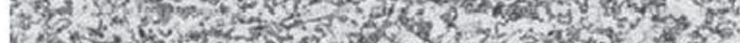
3.

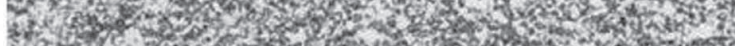
K. (1) H.

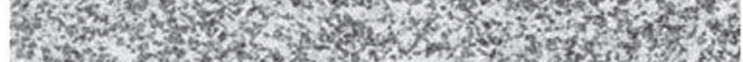

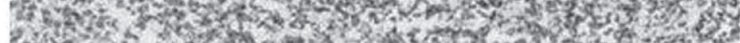

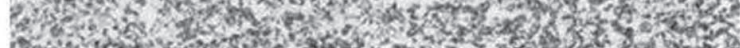

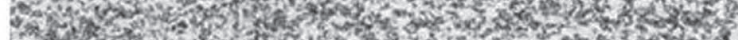

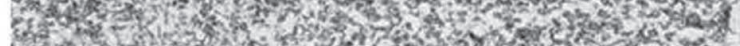

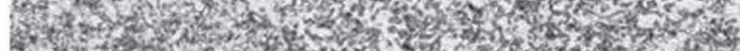

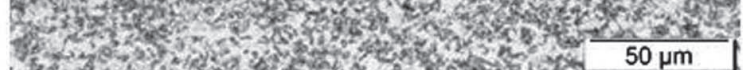

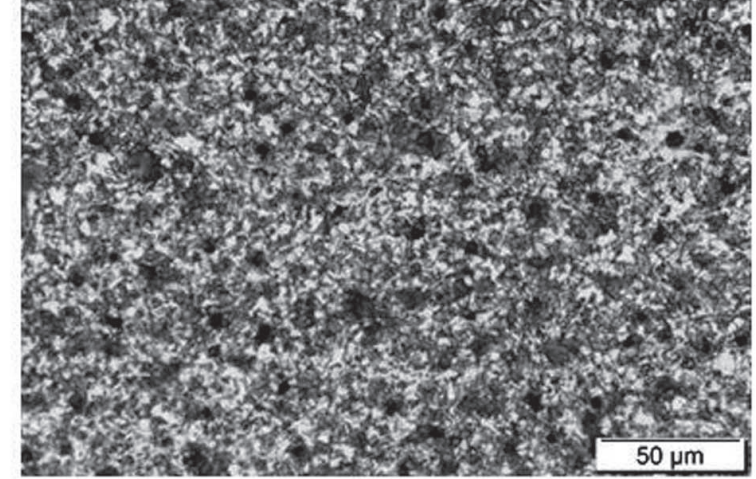

Figura 4. Microestrutura na ZTA adjacente aos passes de enchimento. PF-Ferrita Primária, B-Bainita. 
MP

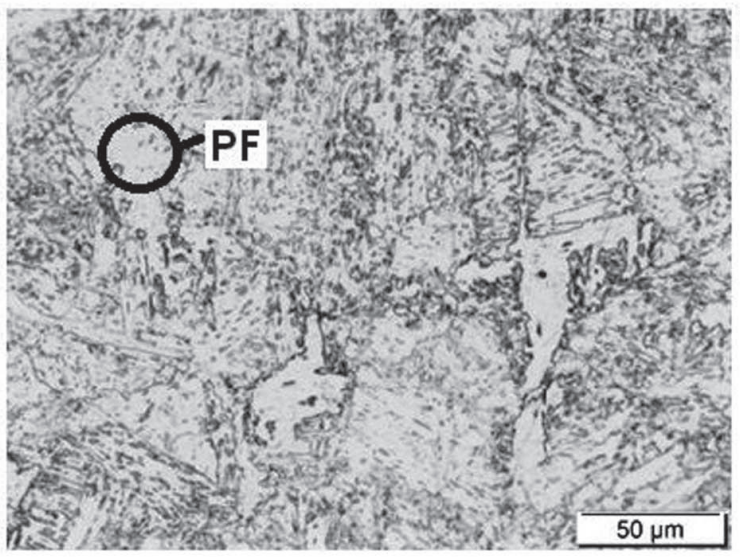

$\mathrm{RP}$

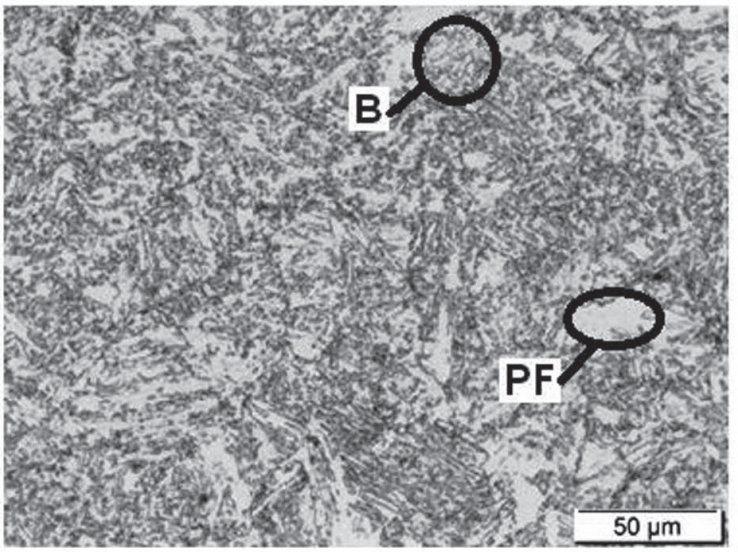

MP

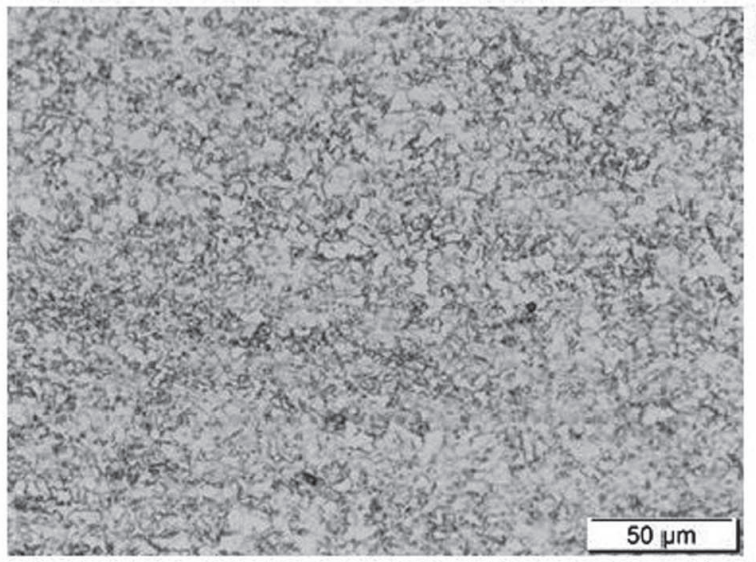

$\mathrm{RP}$

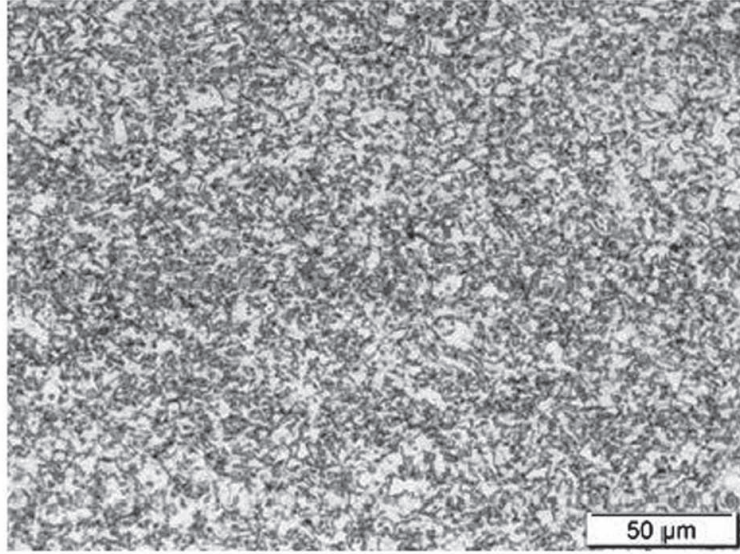

MA

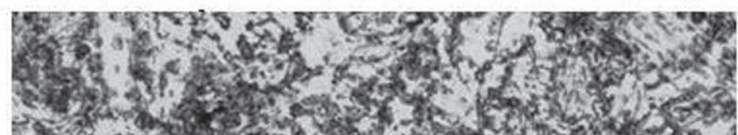
30 . 3 . 2. Hin

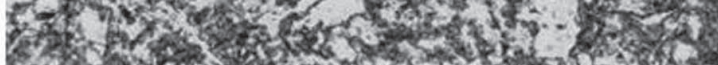

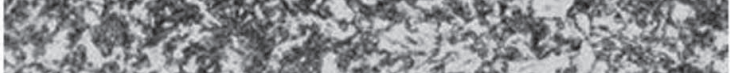

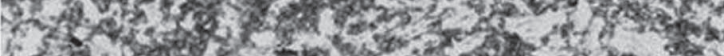
- 3 a

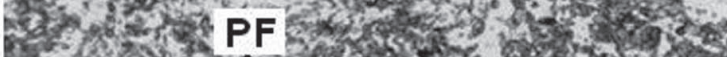

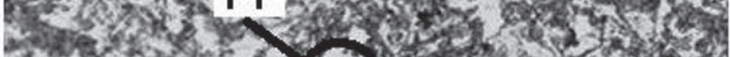

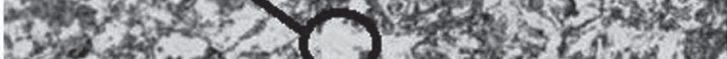
20 .

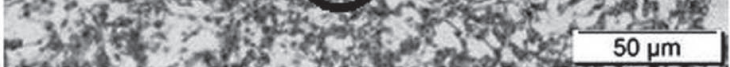

RA

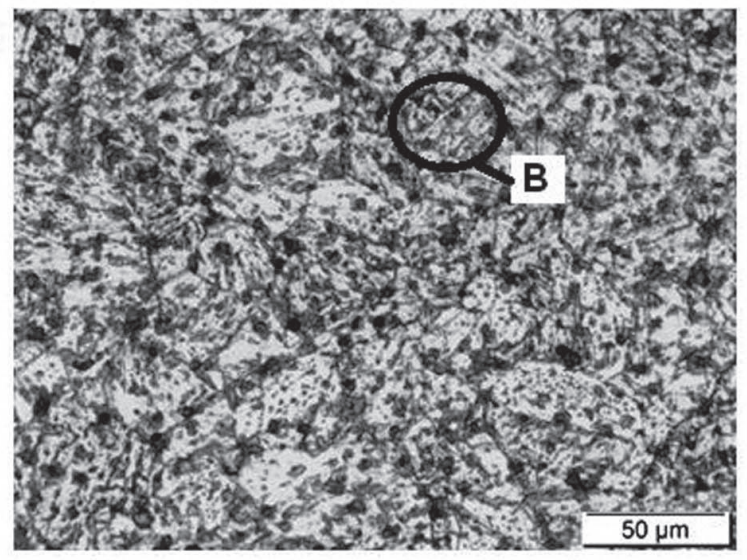

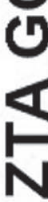

MA

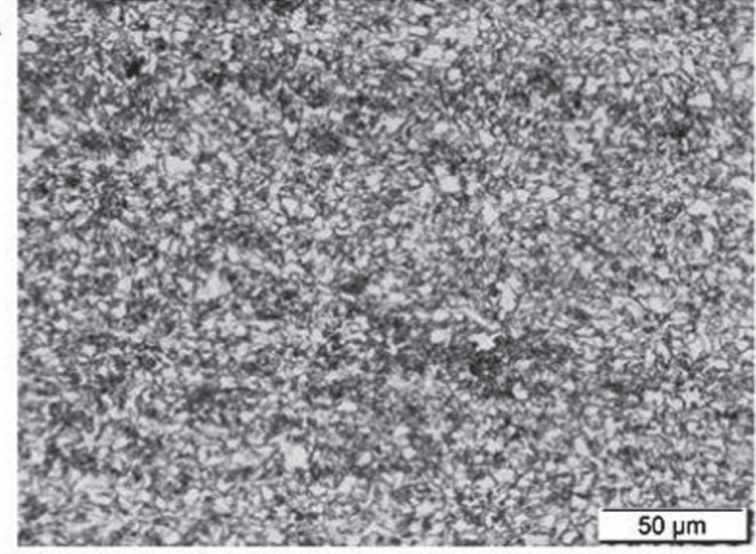

RA
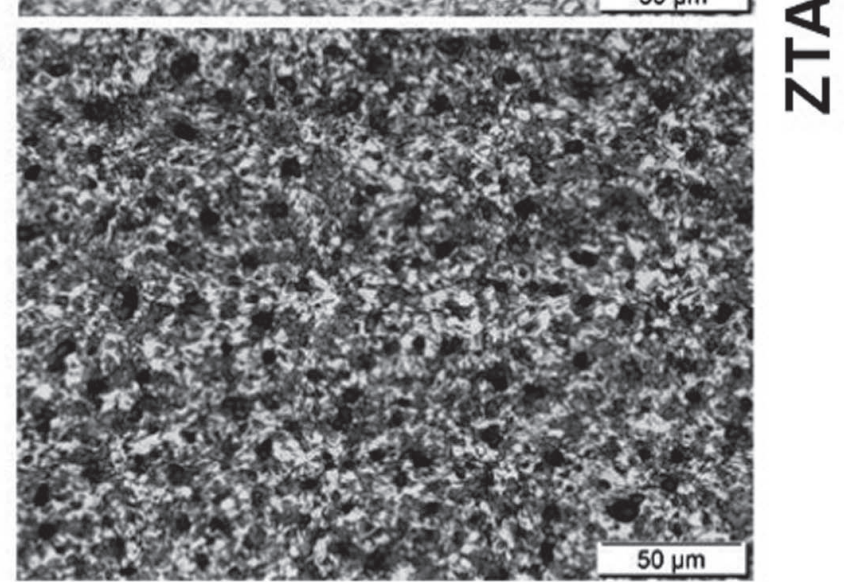

Figura 5. Microestrutura na ZTA adjacente ao passe de raiz. PF-Ferrita Primária, B-Bainita. 
procedimento MA, apresentando picos de alta e baixa dureza, o que poderia ser atribuído à presença isolada de fases com elevada dureza. As maiores temperaturas do procedimento com maior energia de soldagem foram suficientes para promover o aparecimento de ferrita poligonal - PF, que pode ter provocado os pontos de baixa dureza localizados; logo, o controle do aporte térmico torna-se importante na soldagem multipasse do aço API

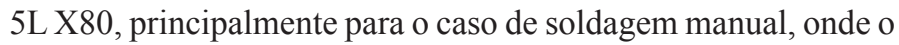
controle dos parâmetros de soldagem é realizado pelo soldador.

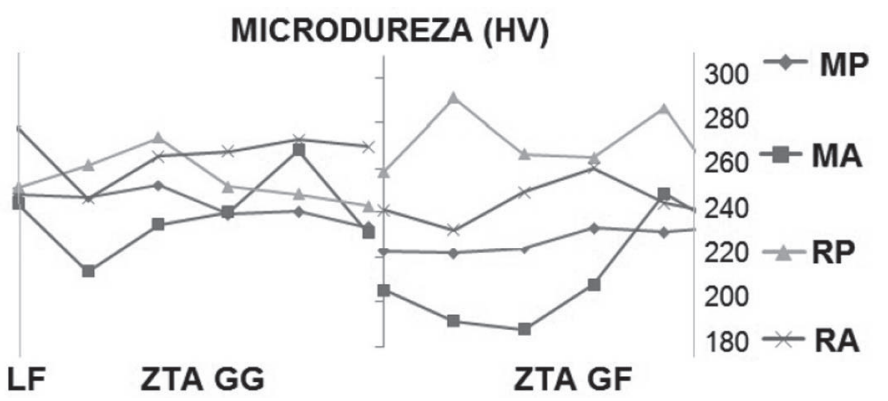

Figura 6 - Medidas de microdureza na ZTA adjacente aos passes de acabamento.

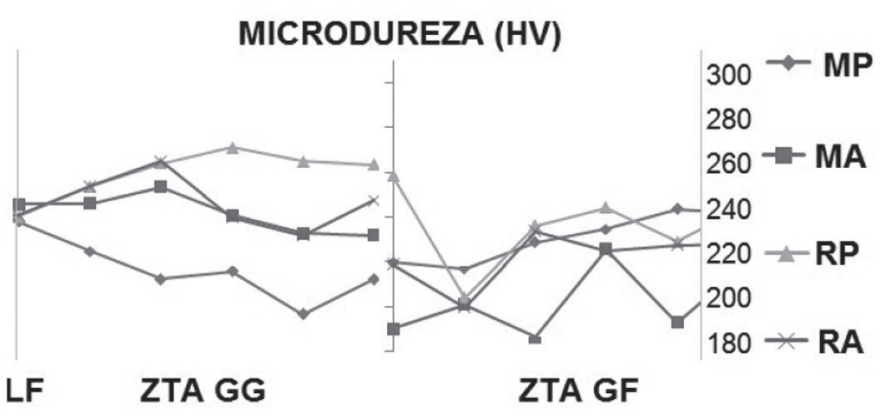

Figura 7 - Medidas de microdureza na ZTA adjacente aos passes de enchimento.

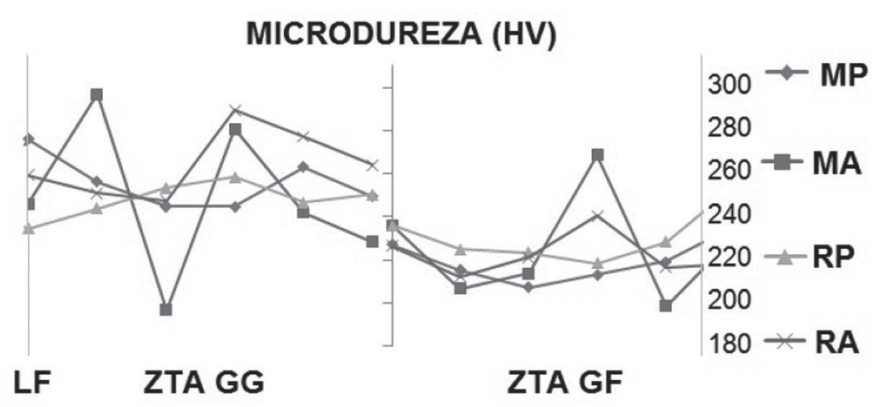

Figura 8 - Medidas de microdureza na ZTA adjacente ao passe de raiz.
Tabela 5 - Valores médios de microdureza na ZTA (HV).

\begin{tabular}{|c|c|c|c|c|}
\hline $\begin{array}{c}\text { PROCEDIMENTO } \\
\text { DE SOLDAGEM }\end{array}$ & $\begin{array}{l}\text { REGIÃO } \\
\text { DA ZTA }\end{array}$ & $\mathrm{ACAB}$ & $\mathrm{ENCH}$ & RAIZ \\
\hline \multirow{2}{*}{ MP } & GF & $\begin{array}{l}227 \\
\pm 5\end{array}$ & $\begin{array}{r}229 \\
\pm 11\end{array}$ & $\begin{array}{l}217 \\
\pm 7\end{array}$ \\
\hline & GG & $\begin{array}{l}243 \\
\pm 7\end{array}$ & $\begin{array}{l}214 \\
\pm 10\end{array}$ & $\begin{array}{l}251 \\
\pm 8\end{array}$ \\
\hline \multirow{2}{*}{ MA } & GF & $\begin{array}{l}208 \\
\pm 24\end{array}$ & $\begin{array}{c}199 \\
\pm 16\end{array}$ & $\begin{array}{l}225 \\
\pm 28\end{array}$ \\
\hline & GG & $\begin{array}{l}239 \\
\pm 19\end{array}$ & $\begin{array}{l}241 \\
\pm 9\end{array}$ & $\begin{array}{l}248 \\
\pm 38\end{array}$ \\
\hline \multirow{2}{*}{$\mathrm{RP}$} & GF & $\begin{array}{l}273 \\
\pm 15\end{array}$ & $\begin{array}{l}234 \\
\pm 20 \\
\end{array}$ & $\begin{array}{l}226 \\
\pm 7 \\
\end{array}$ \\
\hline & GG & $\begin{array}{l}256 \\
\pm 12\end{array}$ & $\begin{array}{l}263 \\
\pm 6\end{array}$ & $\begin{array}{l}250 \\
\pm 5\end{array}$ \\
\hline \multirow{2}{*}{ RA } & GF & $\begin{array}{l}245 \\
\pm 10\end{array}$ & $\begin{array}{c}221 \\
\pm 13\end{array}$ & $\begin{array}{l}223 \\
\pm 11 \\
\end{array}$ \\
\hline & GG & $\begin{array}{c}264 \\
\pm 10\end{array}$ & $\begin{array}{c}248 \\
\pm 12\end{array}$ & $\begin{array}{r}264 \\
\pm 17\end{array}$ \\
\hline
\end{tabular}

\section{Conclusões}

- A microestrutura presente na ZTA de grão grosseiros nos procedimentos de soldagem com processo manual e eletrodo revestido apresentou uma maior proporção de ferrita primária grosseira; enquanto que empregando processo robotizado, observou-se uma microestrutura mais refinada com formação de bainita.

- O tamanho médio de grão na ZTA de grãos grosseiros foi menor quando utilizou-se procedimento de soldagem robotizado, principalmente para posição de soldagem vertical ascendente; a granulometria na ZTA de grãos refinados não apresentou variações consideráveis com relação ao procedimento de soldagem utilizado, seja ele manual ou robotizado, porém, ocorreu um maior refino para posição de soldagem vertical ascendente.

- A extensão média da ZTA apresentou-se menor para os procedimentos empregando processo de soldagem robotizado, com reduções da ordem de $54,5 \%$ na região adjacente aos passes de enchimento.

- Os valores médios de microdureza na ZTA GG foi ligeiramente superior nos casos empregando procedimento robotizado, principalmente quando comparado com as soldagens manuais executadas com maior energia de soldagem.

\section{Agradecimentos}

Ou autores agradecem à Confab pela doação das chapas de aço, à ESAB pelo fornecimento do consumível, à ANP suporte financeiro e bolsa de pesquisa e ao LRSS-UFMG por disponibilizar o robô para soldagem. 


\section{Referências Bibliográficas}

[1] AMERICAN PETROLEUM INSTITUTE - API 5L, Specification for Line Pipe. Washington, 42nd ed. January 2000. $153 \mathrm{p}$.

[2] Kothe, A., J. Richter, A. Guth, B. Musgen, and H. Baumgardt. 1993. "Structure/Property Relationships in HSLA Steel with Low Carbon and Manganese and Increased Silicon Content". Journal de Physique IV Colloque C7, supplement au Journal de Physique III. 3.

[3] Gorni, A. A., Silveira, J. H. D. e Reis, J. S. S.,2007, "Estudo avalia o desenvolvimento de chapas de aço com grão ultra-fino", Corte e Conformação de Metais, Vol. 3, No. 27, pp.78-105.

[4] ASSIS, C. L. F., MONTANARI, L., RODRIGUES, A. R., GALLEGO, J., SILVA NETO, O. Refino de grão em aços baixo carbono: uma revisão crítica. Em: VI Congresso Brasileiro de Engenharia de Fabricação, 2011, Caxias do Sul. VI Congresso Brasileiro de Engenharia de Fabricação, 2011.

[5] ALMEIDA, D. M., MAIA, N. S., BRACARENSE, A.Q., MEDEIROS, E. B., MACIEL, T. M., SANTOS, M. A., "Characterization of Steel Pipeline Damage Using Acoustic Emission Technique”. Soldagem \& Inspeção, v. 11, p. 309-316, 2007.

[6] SILVA, M. C. Determinação Experimental da Tenacidade à Fratura da Zona Termicamente Afetada de Junta Soldada de Aço API 51 X80. Escola Politécnica da Universidade de São Paulo. São Paulo-SP, p. 114. 2009. (Tese de doutorado).

[7] LAITINEN, R. Improvement of Weld HAZ Toughness at Low Heat Input by Controlling the Distribution of A-M Constituents. University of Oulu- Academic Dissertation. Oulu, Finland, p. 204. 2006. (ISBN:951-42-8001-6/ ISSN: 0355-3213).

[8] DAVIS, C. L.; KING, J. E. Cleavage Iinitiation in Intercritically Reheated Coarse-Grained Heat Affected Zone: Part I. Fractographic evidence. Metallurgical and Materials Transactions A, v. 25A, p. 563-573, March 1994.

[9] SANT'ANNA, P. C. Influência de Tratamentos Térmicos Intercríticos na Microestrutura e Propriedades Mecânicas do Aço API 5L X65. Universidade Estadual de Campinas - Faculdade de Engenharia Mecânica. Campinas - SP. 148f. 2006. (Tese de Doutorado).

[10] BHADESHIA, H. K. D. H.; HONEYCOMBE, R. W. K. Steels - Microstructure and Properties. 3. ed. [S.1.]: Published by Elsevier Ltd., 2006.

[11] PINTO, L. C. M., Quantikov - Um analisador microestrutural para o ambiente Windows TM. Tese de Doutorado, Universidade de São Paulo-USP, IPEN, (1996).

[12] ASTM E112. Standard Test Methods for Determining Average Grain Size. American Society for Testing and Materials - ASTM E112-10.

[13] ASTM E384. Standard Test Methods for Knoop and Vickers Hardness of Materials. American Society for Testing and Materials - ASTM E384-10.

[14] ALMEIDA, D. M. MAIA, N. S., BRACARENSE, A. Q.,
MEDEIROS, E. B., MACIEL, T. M., SANTOS, M. A.. "O Uso de Emissão Acústica para Caracterizar Danos na ZTA de Aços ULCB". Anais do $7^{\circ}$ Congresso Iberoamericano de Engenharia Mecânica, México - 2005

[15] FAIRCHILD, D. P., Local Brittle Zones in Structural Welds, in Welding Metallurgy of Structural Steel, 1987, p. 303-318.

[16] DURAND, R. Z. S. Avaliação da Microestrutura e Propriedades Mecânicas da Soldagem Circunferencial do Aço API 5L X80 por Prodessos de Soldagem Semi-Automatica com Proteção Gasosa. Dissertação de Mestrado - PUC. 2007.

[17] EROGLU, M.; AKSOY, M. "M. Effect of initial grain size on microstructure and toughness of intercritical heat affected zone of a low carbon Steel", Materials Science \& Engineering: A. vol. A286, 2000. p. 289-297.

[18] LINNERT, G. E. welding Metallurgy - Carbon and Alloy Steels. 4th ed. Miami: American Welding Society, 1994. 940 p.

[19] ORDÓNEZ, R. E. C. Soldagem e Caracterização das Propriedades Mecânicas de Dutos de Aço API 5L X80 com Diferentes Arames Tubulares. Unicamp. São Paulo - SP, p. 130p. 2004. (Dissertaçao de Mestrado) 